\title{
Using video-Based on Tasks for Improving Mathematical Practice and supporting the productive struggle in Learning Math among Student Teachers In the Faculty of Education
}

\author{
Marwa Nabil El-ahwal, Amir Shahin² \\ ${ }^{1}$ Department of Curricula and Methods of Teaching Mathematics, Faculty of Education, Tanta University, Egypt \\ ${ }^{2}$ Digital Design and Publishing Research Unit (DDPRU), Faculty of Education, Tanta University, Egypt
}

\begin{abstract}
The main objective of the current research is to identify the use of video-Based on Tasks to improve Mathematical Practice and support the productive struggle in learning mathematics among teachers of the faculty of Education. The research tools were prepared and adjusted that included a test, score card, and support for productive struggle in mathematics learning. Basically, it was applied to a sample consisting of (20 male and female students) from the third-year students at the Faculty of Education, Tanta University. The study adopted the quasi-experimental curriculum with experimental design (pre-design after one group). In effect, the findings of the research manifested the effectiveness of using video-Based on Tasks to improve mathematical practices and support the productive struggle of student teachers in the faculty of Education. Accordingly, it was recommended to pay attention to international standards for mathematical practices and effective mathematical teaching practices. In addition, it is vital to pay attention to employing video-based tasks and activating them within the school curriculum.
\end{abstract}

Keywords: Mathematical Practice - video-Based on Tasks - Support Productive Struggle - Mathematics Education - Teacher Students.

\section{Introduction}

Earlier, the development of curricula - especially mathematics - has been featured by depth and breadth; in terms of content, concepts, research methods and teaching methods. Hence, many countries, especially the developed ones, seek to develop methods of teaching mathematics. The role of the National Council of Teachers of Mathematics in developing mathematics education is no secret. Mathematics standards have evolved until it reached the issuing of the Common Core of Mathematics Standards by the National Center for Referees Association for Best Practices for the United States. ( Common Core State Standards for Mathematics, 2010) include Standards for Mathematical Practice, which represents the students practices when learning mathematics:

1- Assimilating the mathematical problem and persevering until solving it.

2- Providing abstract and quantitative inference.

3- Building practical assumptions and criticizing the way others deduce.
4- Using mathematical models.

5- Using the appropriate tools strategically.

6- Paying attention to mathematical precision.

7- Searching for and using the mathematical structure.

8- Finding and expressing a systematic pattern in repeated conclusions.

As a result of implementing the Common Core Standards of Mathematics, a deep understanding of mathematical practice will be achieved. Although traditional teaching methods have succeeded in helping students achieve mathematical skills, there is a need to try other teaching methods in an attempt to increase a deep understanding of mathematical practices and their application to problem solving. Primarily the traditional teacher-centered lecture method is ineffective in teaching students, due to the lack of time for both lecture sessions and problem-solving sessions in the classroom. 
In fact, the lack of a deep understanding of mathematical practices is due to the lack of time invested in solving problems, where the teacher is usually directed to complete a wide curriculum in an insufficient time. In addition, when students are given more time to work on complex mathematical

problems while providing support from colleagues and the teacher, they benefit and increase the level of understanding of their mathematical practices (Zeineddine, 2018). Thus using the video helps the teacher providing the time and flexibility to create a studentcentered learning environment. In this type of classroom environment, teachers can begin implementing the mathematics teaching practices pardoned by the National Council of Mathematics Teachers (NCTM) in the " Chart of Principles for Implementation: Ensuring Mathematical Success for All" (Albanese and Bush, 2015).

In fact, the main difference between the traditional curricula and the curricula used in the method of videosupported assignments lies in the role of technology in teaching. The mathematics program is effective if mathematical tools and technology are combined as primary resources to help students learn and understand the meaning of mathematical ideas, reasoning, and mathematical communication. (NCTM, 2014), For many years ago, educators attempted to find ways to implement structural theory in the classroom. Technology-enhanced learning environments were known as combined learning environments. Hence, the video-supported learning environment provided great opportunities for implementing constructivism with the help of technology. Therefore, such learning method was known as blended learning in a constructive learning environment (Felder, 2012; Strayer, 2012). He also stressed (Shahin, A\& Elfar, , 2017) SUPOURT with information and communications technology performance teaching skills for students. And study (Shahin, 2020). The increased use of modern technologies, And employing them in the teaching and learning processes, and seeking to develop curricula in various specializations by reducing the volume of information by relying on interactive materials and resources in technological environments, It is likely known that technology helps students engage in ways that enhance mathematical practices. For example, Albanese and (Bush,2015) study confirmed the effectiveness of video-supported tasks in promoting engagement, active learning, and solving problems that encourage thinking and building understanding. The study emphasized that there are many benefits to using video, including developing and enhancing mathematical practices among students, enabling students to engage in mathematical practices, as well as increasing the opportunity to build practical hypotheses and criticizing of the way others infer. Learning through video-based tasks is flexible and allows multiple student-centered solution, strategies and enables students to repeat the lesson to help them learn. Of vital importance for mathematics programs is the effective teaching to engage students in meaningful learning, through individual and participatory experiences that enhance their ability to

make meaning out of mathematical ideas and mathematical reasoning. The American National Council of Mathematics Teachers identifies eight teaching practices of mathematics which are the basic teaching skills needed to foster deep learning of mathematics (NCTM, 2014). These eight practices are: setting mathematical goals to focus on learning, implementing tasks that enhance reasoning and problem solving, using and linking mathematical representations, facilitating meaningful mathematical dialogue, asking purposeful questions, building procedural fluency from conceptual understanding, supporting productive struggle in learning mathematics, drawing evidences of student thinking and using. Hence, teachers should improve the teaching and learning that occur in their classrooms and use these eight practices to develop an effective model of education. Generally, the field of teacher preparation is currently undergoing a shift towards curricula that focus on educational practice and courses designed around different educational methods. In addition, facilitating mathematical dialogue in the classroom is seen as a practice of mathematics teaching. A principles document for application (NCTM, 2014)) emphasized that important ways to support teachers are student engagement in mathematical dialogue aimed at supporting productive struggle.

Initiating from the development of the educational process, there is an urgent need to search for new models and strategies for teaching mathematics that work well with students and help them learn mathematics. In effect, they should be conducted scientifically, so that others can understand them more. According to previous literature, the researchers found that the most recent trends in methods of teaching mathematics is the use of "videobacked assignments" which are strategies that may help teachers to teach mathematics in less time. Students are introduced to the lecture materials through a mixture of online notes and a pre-recorded lecture by the researcher or other sources. In addition, the accompanying task is completed at the end of the video to encourage students to watch the videos. Then students are asked to undertake tasks that challenge their ideas and abilities through group activities Pre-designed to implement the lesson in class with teacher guidance , Moreover, studies emphasized, including study (Warshauer \& Kawaguchi,2015) that struggling to make sense of mathematics is a vital constituent of learning mathematics with understanding. Little research on what the struggles look like for school students and how they can be productive are found. This study states that the productive role of student struggle can add to supporting "doing mathematics and its implications on student learning with understanding. Teachers and instructional designers 
can use this framework as a tool to integrate student struggle into tasks and instructional practices.

In response to the ongoing call that requires research on the implications of employing video-Based on Tasks to improve mathematical practices and also the need to employ educational videos that are available to everyone, technology has become a large part of education in schools.

\section{Methodology:}

Basically the current research depends on designing its procedures on one of the Quasi-experimental research designs, which is a pre-dimensional one-group design, in order to identify the effectiveness of using video-

supported tasks to improve mathematical practices, and support the productive struggle in mathematics education for teachers of the Faculty of Education. The current research problem was determined by the researchers' observation that there is a low level of teacher performance for students in the practice of using mathematical practices and supporting productive struggle in mathematics education. The research problem can be crystalized in the following main question:

" Using video-Based on Tasks for Improving Mathematical Practice and Supporting the productive struggle in Learning Math among Student Teachers in the Faculty of Education". This main question is divided into the following sub-questions:

1. What is the appropriate educational design for employing video-Based on Tasks?

2. What is the effectiveness of using video-Based on Tasks in the light of mathematical practices among student teachers at the Faculty of Education?

3. What is the effectiveness of using video-Based on Tasks to support the productive struggle of student teachers in the Faculty of Education?

Through answering the previous research questions and its application, the current research aims at:

1. Identifying the educational design models to implement the video-Based on Tasks.

2. Preparing tools to measure both mathematical practice and support for productive struggle.

3. Investigating the effectiveness of using videoBased on Tasks for improving mathematical practices and supporting productive struggle in mathematics for student teachers of the faculty of Education.

This research derives its importance from the following:

1- The scarcity of Arabic and national studies that dealt with mathematical practices and teaching practice (support for productive struggle), despite

2- the presence of many foreign studies that dealt with this topic.

3- It is a response to the recent trends in the field of information and communication technology and its applications in the educational field.
4- This research, via focusing on the importance of video education, may benefit researchers in the field of mathematics education by carrying out other research that deals with other aspects of this topic.

5- It may be useful in enhancing the practice of using mathematical practices for the student teachers.

This research was applied in the first semester of the academic year 2019/2020 for the third year students, Mathematics Department, Faculty of Education - Tanta University (the first researcher's work place). The independent variable is the video-Based on Tasks, which is one of the mathematical practices and one of effective mathematics teaching practices "Supporting productive struggle".

The researchers have prepared the tools according to systematic and scientific steps that are subjected to educational design criteria as follows:

The tasks of the researchers: The educational design as well as the criteria for using the tasks supported by the video were determined in the light of the opinions of the arbitrators specialized in the field of educational technology as well as the use of programs to design the video. This is done after the first researcher prepared the lessons used in the mathematics curricula. The second researcher built and designed the content according to the steps of the model followed by the researchers, which includes the following stages:

The first stage: the preparation:

First: General Goals: After defining the general goals, the behavioral goals for each general goal have been formulated, in light of the skills that were reached when formulating the educational goals.

1) The use of mathematical practice.

2) Support the productive struggle in mathematics education through:

- The goals are clear to achieve the ability to make efforts through tasks.

- The goals are clear to achieve attention.

- The goals are formulated to achieve learner`s effectiveness.

- Helping others by finding a solution to the problem.

- Students interact by creating participations that encourage discussion

- Creating an atmosphere of intimacy between students and each other in the

- accomplishment of the task assigned to them.

- Defining tasks in the form of life problems to facilitate their understanding and encourage their solution.

Second: Defining the content:

Content was built in the form of a set of tasks to solve mathematical problems and designing activities on teaching methods and mathematical practice that focus on supporting the productive struggle in mathematics 
education so that each task and activity covers a clear

goal.

The second stage: the production stage:

First: Designing an education strategy for video-Based on Tasks:

When designing the video, the researchers were keen on motivating students and create a willingness to learn. This strategy included the following steps:

1) Providing information (this stage has been accomplished on the educational platform)

- The students presented a video clip that

- corresponds to the subject of the study.

- Students watch the video, take notes or write a list of basic ideas and details.

- Discussions were placed on the educational platform designed around new information or concepts that students have known or absorbed after watching the material.

- Students have reviewed their notes or lists and reduced basic ideas and details in a summary of the material presented.

- Students have shared their summaries on the educational platform.

- Discussing similarities and differences.

2) Information processing (this stage took place inside the classroom)

For the end of improving the mathematical practice, the first researcher offered life tasks. For helping students participate in the activities presented to them, the researcher performed the following:

a. Planning: by providing a general review of the presented concept and activating previous knowledge and experience.

b. The monitoring process: It is a step in which the researcher requests the students to define a goal for the session, represent the skills, the application of skills and solving tasks to verify understanding. In addition the researcher divided the students into groups which works independently for the end of achieving tasks and the common objectives.

c. Self-reflection and task achievement: After students solve life problems that show their activation of behaviors indicating the use of mathematical practices, the researcher asked students to write self-reflections to document

the parts that were not understood and prepare questions that he would like to ask in the classroom.

Second: Designing a task-based learning environment (educational platform): The first researcher designed an educational platform that includes publishing goals, content, duties, educational activities, videos and educational resources which are means of communication and have discussions with students together.

Third: Video design and selection: Through the application of the theory of self-organizing learning, the video was designed and produced to contain the tasks necessary to improve mathematical practices and support productive struggle, and additional educational sources and videos have been used on the Internet

Fourth: Producing the necessary elements for the video: A program was used to create the video and produce static and animated images and another program to explain the text based on infographics and designing HTML pages, as well as presentations and texts.

The third stage: the use phase: The video was used as an educational subject in accordance with the educational strategy, posing mathematical tasks and problems. In addition, students recounted the previous information and knowledge necessary to solve the task, and if the student does not remember a specific concept, he is guided by the appropriate video and viewed the content that was covered in the video and did not understand it. Then students set learning goals after watching the video. The video allows the student to pause registration and try to solve before watching the interpretation provided by the narrator, as the narrator pauses regularly. The narrator asks, "What will be the next step," and gives the student time to think. After completing the video, the student is asked to self-assess his performance by trying to solve the same problem on their own, and trying to solve other problems.

The fourth stage the evaluation stage: In this step, students make a self-assessment by answering the tasks in the video or writing a report about the goals, expressing an opinion and assessing the extent of the impact of his interaction with his colleagues and the researcher on achieving the allocated goals. The first researcher collected data from the mathematical practice test and the evaluation card for productive support in mathematics.

The fifth stage: The researchers have formulated general criteria by which the requirements for video entry in the educational process are determined, formulated and the grades of evaluation determined according to the requirements of carrying out the research.



Fig (1). Model (El-ahwal\& Shahin, 2020) for using video-Based on Tasks for mathematical practice

\section{Results:}

To find out how well the students 'performance has improved on the mathematical practice test, the second question for the research was," What is the effectiveness 
of using video-Based on Tasks in the light of mathematical practices among student teachers at the Faculty of Education?" To answer this question, the first hypothesis states: "There is a statistically significant difference at the level of significance $(\alpha \leq 0.05)$ between the average scores of students in the pre and post applications to the mathematical practice test, in favor of the post application.

To test the validity of the first hypothesis, the researchers applied the test and used the T-test using the SPSS (22) statistical package to calculate the average differences between the average scores of students in the sample between the pre and post applications, as follows:

Table (1): The value of (T) and the level of its significance for the difference between the average scores of students in the sample in the pre and post applications of the mathematical practice test

\begin{tabular}{l|l|l|l|l|l|l|l}
\hline \multirow{2}{*}{ Test } & $\mathbf{N}$ & Pre & \multicolumn{3}{|c|}{ post } & Df & t \\
\cline { 3 - 6 } & Mean & $\begin{array}{c}\text { Std. } \\
\text { Deviation }\end{array}$ & Mean & $\begin{array}{c}\text { Std. } \\
\text { Deviation }\end{array}$ & & \\
\cline { 3 - 7 } & 20 & 3.30 & 0.66 & 7.25 & 0.44 & 19 & 25.73 \\
& & & & & & \\
\hline
\end{tabular}

*Significance (0.05)

Table (1) illustrates the following:

1- The average scores of the post-performance is higher than the average scores for the pre

2- performance of students of the sample for testing mathematical practices; that the students in the pre performance got an average of (3.30) and in the post-performance scores an average of (7.25), which reflects the increase in the performance of the teachers 'students in the test. In the meantime, the standard deviation of the scores of the students on the mathematical practice test are closely related to that the deviation of the post application $=0.66$ and the deviation of the pre application $=0.44$

3 - The value of $(T)=25.73$, which is a statistically significant value at the level of significance $(0.05)$. This indicates the presence of a statistically significant difference between the students 'degrees in the pre-application and post-application of the mathematical practice test, which results in the effectiveness of the experimental treatment material used in the research.

Thus, the first hypothesis of the research was validated stating that there is a statistically significant difference at the level of significance $(\alpha \leq 0.05)$ between the average scores of students in the pre and post applications to the mathematical practice test in favor of the post application. This was demonstrated by the fact that they solve many life problems, by determining the important quantities in the situation and converting the situation into an illustration and representation in the table and using symbols to solve the problem and interpret the equations that the student used to ensure that the situation is accurately represented.

The researchers also calculated the effect size using the $\eta 2$ equation. And by relying on the values of $(\mathrm{T})$ resulting from the comparisons between the average scores of the pre and post application of the mathematical practice test.

Table (2): The magnitude of the impact of mission-based video use to improve mathematical practices

\begin{tabular}{|l|l|l|l|l|l|}
\hline \multicolumn{1}{|c|}{ Tool } & df & $\mathbf{t}$ & $\left(\boldsymbol{\eta}^{\mathbf{2}}\right.$ & $\mathbf{( d )}$ & $\begin{array}{c}\text { Effect } \\
\text { size }\end{array}$ \\
\hline $\begin{array}{l}\text { Mathematics } \\
\text { practice test }\end{array}$ & 19 & $\begin{array}{l}25 . \\
73\end{array}$ & 0.97 & $\begin{array}{l}8.3 \\
4\end{array}$ & Big \\
\hline
\end{tabular}

According to table (2):

The value of $\eta^{2}$ is $(0.98)$; this means that $(98 \%)$ of the variance in the use of mathematical practices (dependent variable) is due to the employment of video-Based on Tasks (independent variable), and the value of $(\mathrm{d})=10.33$ referring to the large influence size of the independent variable.

Third: Analyzing and processing data related to the growth of the practice of teaching and supporting the productive struggle in mathematics education through a student performance assessment card for a mathematics teacher. To find out how well the teachers 'performance has improved, the research question was," What is the effectiveness of using video-Based on Tasks to support the productive struggle of student teachers in the Faculty of Education? "

For validating the second hypothesis, which states that "There is a statistically significant difference at the level of $\alpha \leq 0.05$ ) between the average scores of student teachers in the pre and post applications of an evaluation card to support the productive struggle in mathematics education in favor of the post application". The first researcher applied an evaluation card for teaching and supporting productive struggle in mathematics education. she used the T-test using the SPSS statistical package to calculate the average differences between the average scores of students in the sample in the evaluation card supporting productive struggle in mathematics education between the pre and post applications, as follows:

Table (3): The value of (T) and the level of its significance for the difference between the average scores of students of the students of the sample in the pre and post applications on the evaluation rubric supporting productive struggle in mathematics education.

\begin{tabular}{|c|c|c|c|c|c|c|c|}
\hline \multirow[b]{3}{*}{ Test } & \multirow[t]{2}{*}{$\mathrm{N}$} & \multicolumn{2}{|c|}{$\operatorname{Pr}$} & \multicolumn{2}{|r|}{ post } & \multirow[b]{2}{*}{$\mathrm{df}$} & \multirow[b]{2}{*}{$\mathrm{T}$} \\
\hline & & Mean & $\begin{array}{l}\text { Std. } \\
\text { Deviation }\end{array}$ & Mean & $\begin{array}{l}\text { Std. } \\
\text { Deviation }\end{array}$ & & \\
\hline & 20 & 12.4 & 0.68 & 24.2 & 1.43 & 19 & 29.4 \\
\hline
\end{tabular}

*Significance $(0.05)$

Apparently, table (3) manifests that The average scores of the post-performance are higher than the average scores of the post-performance for students of the sample on the dimensions of the evaluation card for the productive struggle support in mathematics education and the card as a whole. In detail, the students in the pre-performance got an average (12.4) and in the post-performance scores achieve an average of (24.2). This indicates that the students have the skill of supporting the productive struggle in mathematics education which is evidenced through their teaching performance. The standard 
deviation of the degrees of students of the sample members on the evaluation card of productive struggle support in mathematics education in post-application is higher than the pre-application.

It is also clear that the value of $(\mathrm{T})=29.4$, which is a statistically significant value at the level of $(0.05)$. This indicates that there is a statistically significant difference between students 'grades in the pre and post application of the evaluation card supporting productive struggle in mathematics education, which reflects the effectiveness of Experimental treatment material. Accordingly, the null hypothesis was rejected and the alternative hypothesis was accepted. There is a statistically significant difference at the significance level of (0.05) between the average scores of student teachers in the pre and post-application scores for the productive struggle support card in favor of postapplication. In addition, the value of $\eta^{2}$ is (0.97); this means that $(97 \%)$ of the variance that occurred in support of the productive struggle in mathematics education (dependent variable) is due to the employment of video based on the task (independent variable). Plus the value of (d) $=9.53$, which expresses the large influence size of the independent variable. The foregoing shows the effectiveness of task-based video in supporting productive struggle in mathematics education.

\section{Discussion}

The current study showed the impact of using video-Based on Tasks to improve Mathematical Practice and support the productive struggle in mathematics learning for student teachers of the Faculty of Education. It was based on the strategy presented in the current research methodology through interaction between students and video tasks via the platform used, and building content in the form of a group Among the tasks for solving mathematical problems and designing activities about teaching methods and mathematical practice that focus on supporting the productive struggle in mathematics education so that each task and activity covers a clear goal of the goals that were formulated to achieve the required mathematical practices Their knowledge, as well as achieving the productive struggle in mathematics education when they showed students making efforts through tasks, creating the ability to achieve the required attention, as well as achieving effectiveness in learning through achievement in mathematical problems., And finding a solution to these problems, as well as posts that encourage discussion, blogging Notes or writing a list of basic ideas and details after watching the video clip. All of this has real aspects that help support performance in achieving the productive struggle in teaching mathematics.

\section{Conclusion:}

According to the findings of research, it is possible to seek to investigate students' perceptions about the educational effectiveness of video use, the impact of the use of interactive video on improving the academic performance of middle school students, the effectiveness of missionbased video to support student teacher involvement during and before service, and task-designed discussions about information or new concepts that students have known or absorbed after watching the material through analyzing students 'work by relying on learning analysis programs according to modern technologies.

\section{Recommendations:}

Based on the findings, the researchers recommend training faculty members in colleges of education and those working in the educational field who are lecturing on designing tasks based on the educational video and integrating them into the classroom for mathematics. In addition, teachers should include more interactive video presentations within their curricula and designed according to the current model. In addition, it is vital to pay attention to employing video-based tasks and activating them, as one of the tools for providing different levels of assistance, and guidance for developing some skills in other courses in light of clear educational standards, and paying attention to standards for international mathematical practices and effective teaching mathematics.

\section{References}

[1] Shahin, A. (2020). Employing infographics based on tablet applications to improve professional competence in the light of the digital transformation of education technology specialists. International Journal of Instructional Technology and Educational Studies, 1(1), 2224. doi: 10.21608/ihites.2020.28769.1006

[2] Shahin, A, Elfar, (2017): Impact Of The Use Of TPACK Learning Significative With Information And Communications Technology Performance Teaching Skills For Students Of The Faculty Of Education, Curriculum And Instruction And Technology Education 1 (1), 33

[3] Albanese, J. and Bush, S. B. (2015, March). The Flipped Classroom: An Avenue for Student-Centered Learning, mathematics teaching in the middle school, 20(Common Core State Standards Initiative (2010). Common Core State Standards for Mathematics, National Governors Association Center for Best Practices and the Council of Chief State School Officers, Washington.

[4] Felder, R.M. (2012). Engineering education-A tale of two paradigms. In SFGE, 2nd. Int Conf on Geotechnical Engineering Education, Galway.

[5] National Council of Teachers of Mathematics. (2014). Principles to actions: Ensuring mathematical success for all. Reston, VA: National Council of Teachers of Mathematics.

[6] Strayer, J. F. (2012). How learning in an inverted classroom influences cooperation, innovation and task orientation. Learning Environments Research, 15(2), 171-193. http://dx.doi.org/10.1007/s10984-

[7] Warshauer, Hiroko Kawaguchi (2015) Productive struggle in middle school mathematics classrooms, Journal of Mathematics Teacher Education, v18 n4. 